08

\title{
Новая технология создания высокочувствительных сегнетопьезоэлектрических материалов на основе гибрида микро- и наноструктурированных полимеров
}

\author{
(C) М.А. Курбанов, ${ }^{1}$ Ф.Н. Татардар, ${ }^{1,2}$, Н.А. Сафаров, ${ }^{2}$ И.С. Рамазанова, ${ }^{1}$ З.А. Дадашев, ${ }^{1}$ \\ И.А. Фараджзаде, ${ }^{3}$ К.К. Азизова, ${ }^{1}$ А.Ф. Гочуева ${ }^{1}$ \\ ${ }^{1}$ Институт фоизики НАН Азербайджана, \\ AZ-1143 Баку, Азербайджан \\ 2 Университет Хазар, \\ AZ-1096 Баку, Азербайджан \\ ${ }^{3}$ Институт радиационных проблем НАН Азербайджана, \\ AZ-1141 Баку, Азербайджан \\ e-mail: tatardar.farida@rambler.ru
}

Поступило в Редакцию 24 июля 2018 г.

В окончательной редакции 25 января 2018 г.

Принято к публикации 18 октября 2018 г.

Изложены результаты исследования по созданию композитов на основе гибрида микро- и наноструктурированных полимерных диэлектриков. Предложена новая технология иммобилизации наночастиц в полимерной матрице композита. При этом в полимерной матрице создаются функциональные электроотрицательные полимерные сегменты, являющиеся главным фактором препятствующих мобилизации наночастиц в полимерной фазе композита.

DOI: 10.21883/JTF.2019.05.47478.2443

\section{Введение}

В настоящее время существуют в основном четыре направления в области создания активных диэлектрических и полупроводниковых материалов: сегнетоэлектрические, полупроводниковые, полимерные и композитные. Любые сочетания вышеуказанных материалов, в свою очередь, сопровождаются получением новых активных материалов. Так, например, сочетание полимера (матрица) с сегнетопьезоэлектрическими материалами (диспергатор) позволяет разработать новые композиты с высокими пьезо- и пироэлектрическими характеристиками. Отметим, что для всех композитных материалов на основе полимерной матрицы характерно обогащение приповерхностного слоя полимером. Поэтому в режиме генерации акустических волн приповерхностный слой является областью потери из-за резкого отличия акустического сопротивления компонентов композита [1-3]. В композитном материаловедении трудной задачей является выравнивание акустических сопротивлений компонентов композита. В настоящее время эта задача решается различными способами: химическими, акустическими и механическими. Полученные экспериментальные результаты позволяют сделать вывод о том, что более эффективным способом является использование плазмы электрического разряда для целенаправленной модификации поверхности полимерных материалов [4-11]. Здесь главным фактором является равномерная обработка поверхности полимера плазмой электрического разряда. Эту задачу можно решить, если в качестве электрического разряда использовать барьерный раз- ряд, т. е. в воздушной среде, ограниченной диэлектриками [2-9]. Это непосредственно связано с возможностью осуществления модификации приэлектродной области полимерной фазы при наличии барьерного разряда и температуры. Такая технология позволяет также равномерно модифицировать полимерную фазу при различной температуре и интенсивности плазмы электрического разряда. Если учитывать, что электрический разряд является активизирующим фактором, то данную технологию можно использовать для прогнозирования параметров плазменных каналов применением оптических методов [12]. Далее, как мы уже отмечали, в настоящей работе необходимо осуществить равномерную обработку полимера и равномерное распределение нанои микрочастиц в полимерной матрице. Более трудной задачей является введение наночастиц в полимер и предотвращение их мобилизации. Поэтому в первую очередь следует создать центры локализации наночастиц в композите. Центры локализации можно создать путем окисления полимерных сегментов в условиях действия плазмы электрического разряда. Образовавшиеся кислородсодержащие группы и сегменты являются центрами захвата и обеспечивают иммобилизацию наночастиц.

Целью настоящей работы является создание новой технологии получения высокоэффективных пьезоэлектрических материалов путем осаждения наноструктурированных полимеров на поверхности микроструктурированных пьезоэлектрических подложек. Для достижения этой цели были решены следующие задачи: 
- получена пьезоэлектрическая подложка путем модифицирования ее поверхности плазмой электрического разряда;

- осуществлена равномерная модификация полимерной макромолекулы, сегментов и кислородсодержащих групп в полимерной цепочке;

- разработана методика иммобилизации наночастиц в полимерной матрице;

- разработана плазменная технология осаждения наноструктурированного полимерного раствора на поверхность пьезоэлектрического композитного элемента.

\section{Методика эксперимента}

Рассмотрены матричные композиты (тип 0-3) на основе пьезокерамики семейства цирконата-титаната-свинца типа ПКР-7М (тетрагональная структуpa), термопластичного полимера полиэтилена высокой плотности ПЭНП с показателем текучести расплава $1.3 \mathrm{~g} / 10 \mathrm{~min}$ (нагрузка $2.0 \mathrm{~kg}$, температура $190^{\circ} \mathrm{C}$ ) и диэлектрика диоксида кремния $\mathrm{SiO}_{2}$. Выбор карбоцепного полимера полиэтилена обусловлен тем, что он характеризуется высокими по производимости, составу, строению и физико-химическими свойствами. Выбор пьезокерамики ПКР-7М (РZТ-5Н) связан с тем, что она имеет высокий пьезомодуль $\left(d_{33}=760 \cdot 10^{-12} \mathrm{C} / \mathrm{N}\right)$, модуль Юнга $\left(Y_{11}^{E}=0.57 \cdot 10^{11} \mathrm{~Pa}\right)$ и диэлектрическую проницаемость $\left(\varepsilon_{33} / \varepsilon_{0}=5000\right)$. Использован пирогенный диоксид кремния $\mathrm{SiO}_{2}$ (аморфный) с размерами частиц в пределах $50-70 \mathrm{~nm}$. Форма частицы - сферическая, плотность $22 \mathrm{~g} / \mathrm{m}^{3}$ и удельная поверхность $200 \mathrm{~m}^{2} / \mathrm{g}$, электропроводность $10^{-12} 1 /(\Omega \cdot \mathrm{m})$. Плазменная кристаллизация композита способствует возникновению активных центров физической и химической природы в полимерной фазе [4,5,13]. Длительность воздействия разряда на полимерную матрицу (обработка) изменялась в пределах от 15 до $30 \mathrm{~min}$ в зависимости от свойств и объемного содержания полимера и пьезокерамики в композите, толщины газового зазора [4,5,14]. Выбранные наночастицы из диоксида кремния $\mathrm{SiO}_{2}$ обладают значительной поверхностной и высокой химической активностью. Высокая поверхностная энергия нанообъектов приводит к возникновению необычных поверхностных свойств и реакций. Поэтому одной из проблем разработки полимерных нанокомпозитов является эффективное диспергирование, стабилизация наночастиц и предотвращение их мобилизации в полимерной матрице композита. Указанные задачи решены применением технологии модификации полимерной фазы в электроотрицательной газовой среде [4,5]. Стабилизирующий эффект объясняется возникновением в условиях действия плазмы электрического разряда в полимерной фазе композита активных центров окисления и субмикроразмерных областей сшивания макромолекул для локализации диэлектрической наночастицы. Это приводит к образованию прочной структуры из

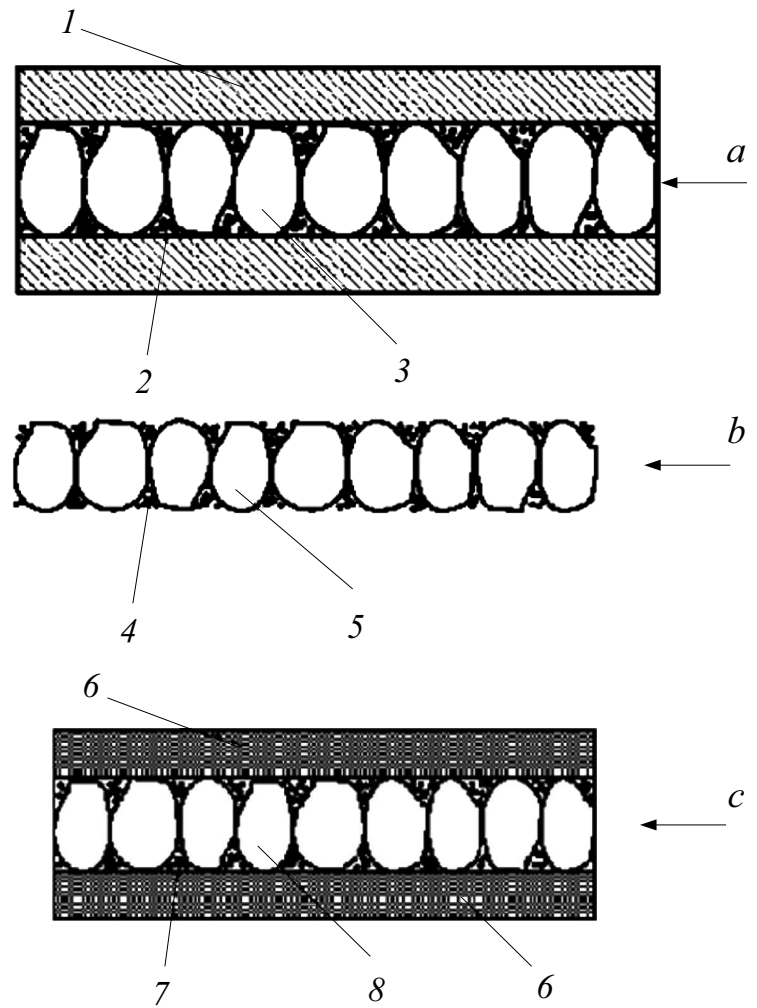

Рис. 1. Структура композита, состоящего из наноSiO 2 и микропьезоэлектрической ПКР-7М. $a-$ микропьезоэлектрический композит ПЭНП-ПКР-7М; $b-$ микропьезоэлектрическая подложка, состоящая из микрочастицы ПКР-7М (пьезокерамика ростовская модифицированная семейства цирконата-титаната свинца); $c-$ гибридный нано- и микропьезоэлектрический композит, состоящий из ПЭНП-ПКР-7М и наночастицы $\mathrm{SiO}_{2} .1$ - приповерхностный полимерный слой; $2-$ межфазный полимерный слой; 3 - пьезочастица; 4 - межфазный слой в случае отсутствия внешнего полимерного слоя; 5 - пьезокомпозитная структура; 6 - приповерхностная наноструктурная полимерная прослойка; 7 - наночастица $\mathrm{SiO}_{2} ; 8$ - гибридные композиты на основе нано- и микроструктурированных композитов.

частиц $\mathrm{SiO}_{2}$, окисленных и сшитых локальных областей макромолекул полимера. При этом наночастицы диэлектрика занимают активные участки в полимерной матрице, не разрушая макроструктуру пьезоэлектрического композита. Необходимо отметить, что усиление полимеров дисперсными нанонаполнителями является фундаментальным вопросом для создания полимерных материалов различных назначений $[10,11]$. Предполагается, что двумя главными факторами усиления являются размер частиц или удельная поверхность наполнителя и связь полимер-наполнитель [10,11]. Отметим, что среди обширного класса полимерных композитов новым типом наполненных материалов являются полимерные нанокомпозиты (НК), в которых, по крайней мере, один из размеров дисперсной фазы (длина, ширина и высота) не превышает $100 \mathrm{~nm}[10,11]$. Из-за уль- 
Пьезоэлектрические, механические, электрофизические и электромеханические параметры композитов ПЭНП - 50\% vol. ПКР-7М и ПЭНП - 0.4 vol. $\mathrm{SiO}_{2}-49.6 \%$ vol. ПКР-7M

\begin{tabular}{|c|c|c|}
\hline \multirow{2}{*}{ Параметры } & \multicolumn{2}{|c|}{ Пьезокомпозиты } \\
\hline & ПЭНП - 50 vol. $\%$ & $\begin{array}{c}\text { ПЭНП }-0.4 \text { vol.\% } \\
\mathrm{SiO}_{2}-49.6 \text { vol.\% PKR }-7 \mathrm{M}\end{array}$ \\
\hline$\varepsilon_{33} / \varepsilon_{0}$ (относительная диэлектрическая проницаемость) & 100 & 140 \\
\hline$K_{31}$ (коэффициент электромагнитной связи при растяжении) & 0.15 & 0.22 \\
\hline$K_{33}$ (коэффициент электромагнитной связи при сжатии) & 0.25 & 0.38 \\
\hline$d_{31} \cdot 10^{12}, \mathrm{C} / \mathrm{N}$ (пьезомодуль при растяжнии) & 50 & 80 \\
\hline$d_{33} \cdot 10^{12}, \mathrm{C} / \mathrm{N}$ (пьезомодуль при сжатии) & 89 & 150 \\
\hline$Q_{m}$ (механическая добротность) & 16 & 96 \\
\hline$Y \cdot 10^{-10}$, Ра (модуль Юнга) & 1.6 & 8.6 \\
\hline $\operatorname{tg} \delta \cdot 10^{2} ; E=5 \cdot 10^{3} \mathrm{~V} / \mathrm{m}$ (тангенс угла диэлектрических потерь) & 0.145 & 0.06 \\
\hline$\left(d_{31} \mathrm{Y}\right)^{2},\left(\mathrm{C} / \mathrm{m}^{2}\right)^{2}$ (показатель удельной акустической мощности) & 0.64 & 47.5 \\
\hline$K_{31}^{2} \cdot Q_{m}($ пьезодобротность $)$ & 0.36 & 4.7 \\
\hline$K_{33}^{2} / \operatorname{tg} \delta$ (электромеханический коэффициент полезного действия) & 43 & 240 \\
\hline$K_{31}^{2} \cdot Q_{m} \varepsilon_{33} / \varepsilon_{0}$ (удельная мощность композитного преобразователя) & 36 & 658 \\
\hline Диаметр пьезоэлемента, mm & 20 & 20 \\
\hline Толщина пьезоэлемента, $\mu \mathrm{m}$ & 250 & 250 \\
\hline Диаметр пьезочастиц, $\mu \mathrm{m}$ & $160-200$ & $160-200$ \\
\hline Диаметр наночастиц, nm & $50-70$ & $50-70$ \\
\hline Структура пьезофазы & Тетрагональная & Тетрагональная \\
\hline Структура наночастиц $\mathrm{SiO}_{2}$ & Аморфная & Аморфная \\
\hline
\end{tabular}

традисперсности неорганического диспергатора (наполнителя) такие системы могут обладать необычными электрическими [4-11], механическими [10,11,15], теплофизическими $[15,16]$ свойствами, которые не имеют микрокомпозиты. Функциональными компонентами полимерных НК могут являться металлы, диэлектрики, полупроводники, органические и неорганические вещества $[10,11]$. Для наших исследований в качестве нанодиспергатора необходимо использовать диэлектрические ультрадисперсные частицы, так как электретные, пьезои пироэлектрические композиты приобретают указанные свойства после их электротермополяризации [16-18], что требует высокого диэлектрического сопротивления и электрической прочности. Композиты указанного типа получены из гомогенной порошковой смеси компонентов. Температура и давление прессования композитов выбраны в пределах $437-463 \mathrm{~K}$ и $30 \mathrm{MPa} \mathrm{соответствен-}$ но. Толщина пьезокомпозита выбрана $250 \cdot 10^{-6} \mathrm{~m}$, а диаметр пьезочастиц - $(160-200) \cdot 10^{-6} \mathrm{~m}$. Пьезоэлектрический модуль композитов определен в квазистатическом режиме с точностью $10 \%$. Отметим, что процесс горячего прессования приводит к дополнительному очищению композита от молекул растворителя и ликвидации микрофазного разделения нано- и микрокопозитов на их границе. Таким образом, создается квазимонолитная структура, на основе которой получаются пьезоэлектрические преобразователи различных назначений с высокими электромеханическими и пьезоэлектрическими характеристиками. Объемное содержание нанофазы варьировано в пределе от 0.1 до $1 \%$.

\section{Экспериментальные результаты и их обсуждение}

На рис. 1, $а$ приведено изображение пьезоэлектрической подложки гибридного композита полимер ПКР-7М. Там же показано изображение пьезоэлектрической подложки, полученной модифицированием исходного композита ПКР-7М - полимер под действием барьерного разряда (рис. $1, b)$. Видно, что действием барьерного разряда можно успешно эрозировать приповерхностную полимерную прослойку. На рис. 1, $c$ приведено изображение наноструктурированного композита в случае одновременного воздействия плазмы электрического разряда и температуры. Считаем, что наноструктурированный полимерный раствор осаждается на поверхность пьезоэлектрической подложки, создавая при этом приповерхностный наноструктурированный композит с высокими физико- механическими, электромеханическими и пьезоэлектрическими свойствами (см. таблицу).

Как уже было отмечено, наноструктурирование приповерхностного слоя осуществляется несколькими способами, которые дополняют друг друга. Более интересным является плазменный метод диагностирования наноструктурирования приповерхностного слоя частицами $\mathrm{SiO}_{2}$. Действительно, по мере осаждения наноструктурированного полимерного раствора заметно изменяются диэлектрические, макроскопические и электрические характеристики разряда в системе метал-диэлектрик-газовая среда-полимерный раствор-композит-метал. Прогноз наноструктурирования композитов является одним из нерешенных проблем 


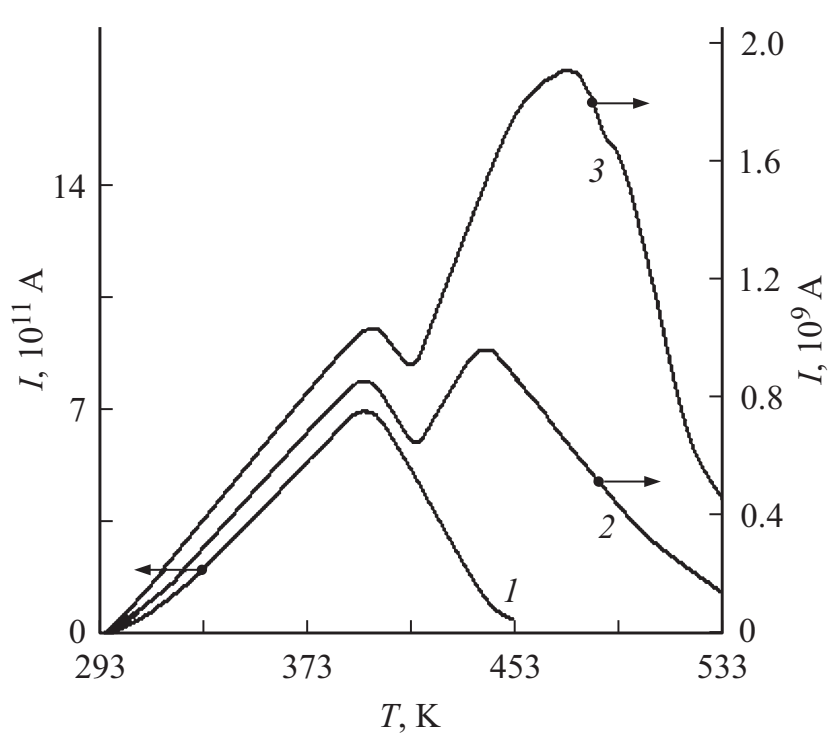

Рис. 2. ТСД-спектры композитов: 1 - спектр исходного полиэтилена; 2 - спектр композита ПЭ-ПКР 2011.7М; 3 - спектр композита ПЭ-ПКР-7М наночастицы $\mathrm{SiO}_{2}$. Объемное содержание ПЭ-50\% (спектр 1), объемное содержание ПКР-7М в композите выбрано 50\% (спектр 2), объемное содержание пьезокерамики ПКР-7М в наноструктурированном композите выбрано 49\%, объемное содержание наночастицы $\mathrm{SiO}_{2}$ в композите выбрано 1\%. Условия поляризации: напряженность электрического поля поляризации $E_{p}=3.6 \mathrm{MV} / \mathrm{m}$; температура поляризации $T_{p}=383 \mathrm{~K}$; время поляризации $t_{p}=0.5 \mathrm{~h}$.

нанотехнологии. Для этого в настоящей работе используется спектр термодеполяризационного тока (рис. 2). Суть метода можно коротко изложить следующим образом: считаем, что если иммобилизация не осуществлялась, тогда ТСД-спектр, полученный для микрокомпозитов, не отличается от ТСД-нанокомпозитов. Этот факт показывает, что наночастицы, добавленные в полимер, мобилизируются как большие кластеры, т.е. они ведут себя как микрочастицы и, следовательно, можно считать, что полученные ТСД-спектры соответствуют спектру микрокомпозитов. Если наноструктурирование композита произошло, то ТСД-спектр должен измениться и температура, соответствующая максимуму спектра, должна смещаться в сторону высоких температур. С этой целью используем вольт-кулоновую и вольт-амперную характеристики диэлектрической структуры (рис. 3, $a$ и $b$ ). Как видно из рис. $3, a$, они имеют нелинейный характер и сопровождаются возникновением тока (рис. $3, a$ ). При одновременном воздействии температуры и плазмы электрического разряда происходит испарение жидкой фазы и ее осаждение на диэлектрическую подложку. В ходе этого процесса в системе с изменением толщины жидкой фазы проявляются нижеизлагаемые эффекты:

- так как толщина жидкой фазы уменьшается при испарении, увеличивается ее емкость, и уменьшается величина напряжения на ней;
- обратный процесс происходит в воздушной прослойке. С испарением жидкой фазы толщина воздушного зазора увеличивается, что приводит к уменьшению ее емкости.

С увеличением толщины воздушного зазора увеличивается напряжение зажигания плазмы (рис. $3, b$ ). Как видно из рис. 3, применением вольт-кулоновой и вольт-амперной характеристик можно диагностировать параметры МДГРКМ (металл-диэлектрик-газовая
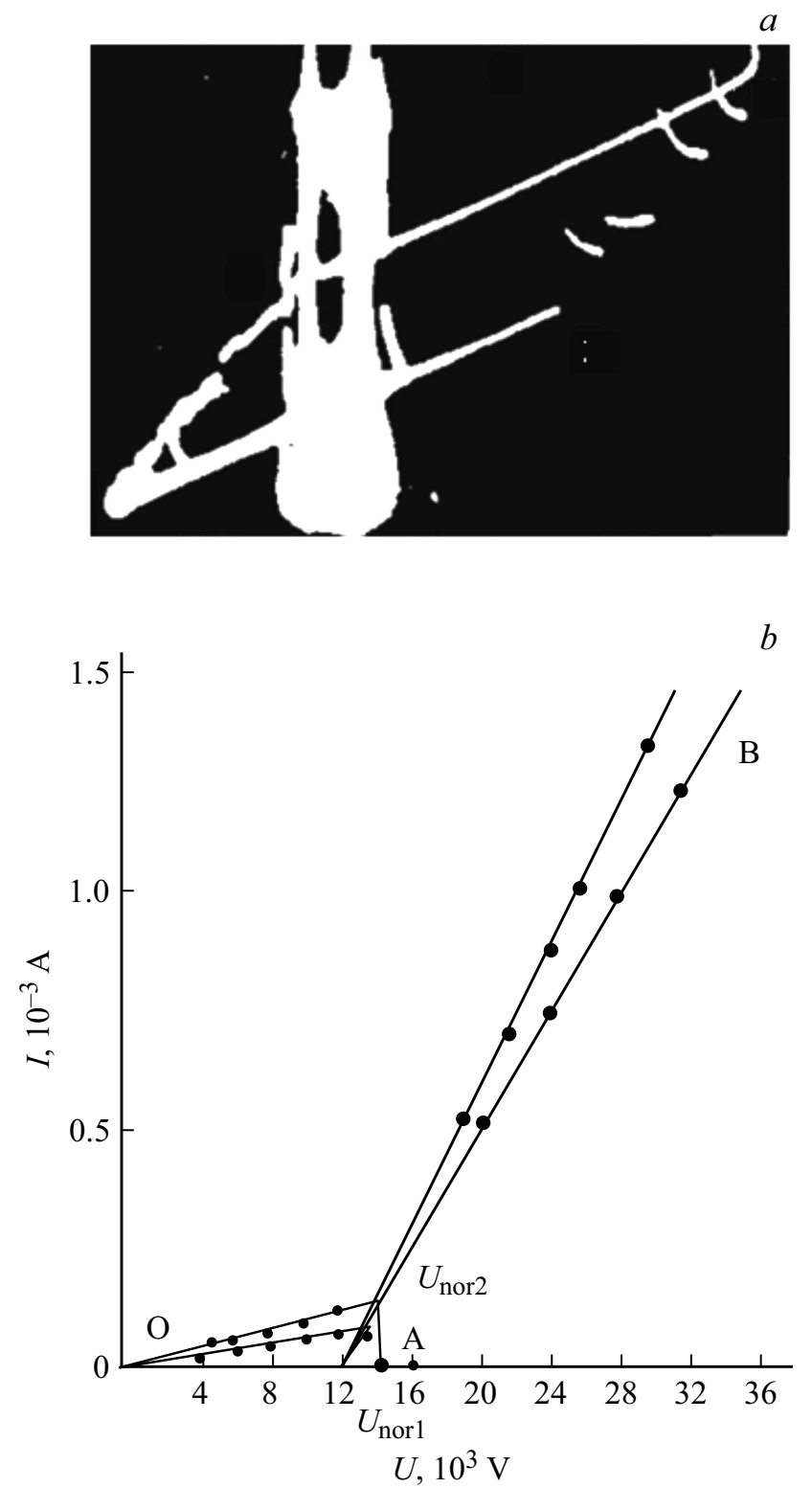

Рис. 3. $a-$ вольт-кулоновая характеристика структуры металл-диэлектрик-газовая среда-полимерный раствор-подложка-диэлектрик-металл. Толщина газового зазоpa $d=4 \mathrm{~mm}$, напряжение зажигания электрического разряда $U=12 \cdot 10^{3} \mathrm{~V} ; b-$ вольт-амперная характеристика ПЭНП. $U_{\text {пог } 1}-$ напряжение погасания разряда в ячейке, $U_{\text {пог } 2-}$ напряжение погашения ячейки в случае испарения полимерной жидкой фазы. А и В - точки, соответствующие напряжению зажигания газового разряда в ячейке. 
среда-полимерный раствор-композит-металл) ячейки. Если учитывать, что вольт-кулоновая характеристика простая и ее параметры важны как фактор носителя информации, то мы сможем целесообразно управлять процессом химического осаждения с помощью этого метода. Очень важным моментом в наших экспериментах является определение точного окончания процесса осаждения или же испарения полимерной жидкой фазы. В противном случае, мы не сможем прогнозировать осаждение полимерной жидкой фазы, так как в местах контакта каналов с поверхностью диэлектрической подложки может происходить интенсивная эрозия. Тогда возникает вопрос, как надо определить момент окончательного испарения жидкой фазы. Для этого проводим следующие исследования:

- определяем напряжение зажигания электрического газового разряда в системе металл-диэлектрик-воздушная прослойка-жидкая фаза-композит-металл;

- определяем напряжение зажигания электрического газового разряда в системе металл-диэлектрик-воздушная прослойка-композит-металл.

Как было отмечено выше, в течение процесса электрохимического осаждения толщина воздушного зазора увеличивается, что и приводит к линейному увеличению напряжения разрядки.

В качестве диагностирующего параметра можно использовать метод определения напряжения зажигания в системе метал-диэлектрик-газовая среда-полимерный раствор-композит-метал. Этот метод является более простым методом и можно использовать его для определения напряжения зажигания разряда и тем самым прогнозировать процесс осаждения полимерного раствора на поверхность пьезоэлектрической подложки. По мере осаждения полимерного наноструктурированного раствора увеличивается толщина воздушного зазора в системе метал-диэлектрик-газовая среда-полимерный раствор-композит-метал. При этом растет и напряжение зажигания разряда (рис. $3, b$ ).

\section{Заключение}

Разработана новая технология микро- и наноструктурирования гибридных композитов. Предложена новая методика получения гибридного композита с высокими пьезоэлектрическими, механическими и электромеханическими свойствами.

\section{Список литературы}

[1] Квашнин C.E. Ультразвуковые электроакустические преобразователи и волноводы - инструменты для медицины. М.: МГТУ, 1999. 250 c.

[2] Керимов М.К., Курбанов М.А., Байрамов А.А., Мехтили А.А., Татардар Ф.Н., Кулиева Г.Х., Оруджев И.Н., Рамазанова И.С. // AMEA - nın mэruzэlэri. 2011. cild LXVII. № 2. P. 39-50.
[3] Нуриев М.А. Автореф. канд. дис. Физико-технологические особенности создания биморфных пьезокомпозитов для акустоэлектрических преобразователей. Баку, 2004, 21 с.

[4] Керимов М.К., Курбанов М.А., Агаев Ф.Г., Мусаева С.Н., Керимов Э.А. // ФТТ. 2005. Т. 47. Вып. 4. С. 686-690.

[5] Курбанов М.А., Султанахмедова И.С., Керимов Э.А., Алиев Х.С., Алиев Г.Г., Гейдаров Г.М. // ФТТ. 2009. Т. 51. Вып. 6. С. 1154-1160.

[6] Керимов М.К., Курбанов М.А., Мехтили А.А., Алиев Г.Г., Султанахмедова И.С., Татардар Ф.Н., Юсибова У.В., Кулиева Г.Х., Яхъяев Ф.Ф. // ЖТФ. 2011. Т. 81. Вып. 8. C. $127-134$.

[7] Курбанов М.А., Татардар Ф.Н., Мехтили А.А., Алиев Г.Г., Яхъяев Ф.Ф., Юсибова У.В. // Электронная обработка материалов. 2011. Т. 47. Вып. 1. С. 87-95.

[8] Kurbanov M.A., Bayramov A.A., Safarov N.A., Tatardar F.N., Mextili A.A., Sultanaxmedova I.S. Hybrid Piezoelectric Composities with High Electromechanical Characteritics. US Patent N 8, 030, 829, 2011.

[9] Kerimov M.K., Bayramov A.A., Mamedov A.A., Mamedov A.I. / Ed. by. J. Cuppoletti. Book 3. Intect Open Access Publisher, 2011. P. 375-404.

[10] Помогайло А.Д., Розенберг А.С., Уфлянд И.Е. Наночастицы металлов в полимерах. М.: Химия, 2000. 672 с.

[11] Азеренков Н.А., Береснев В.М., Погребняк А.Д., Маликов Л.В., Турбин П.В. Наноматериалы, нанопокрытия, нанотехнологии. Х.: ХНУ им. Каразина В.Н., 2009. 209 с.

[12] Завойский E.К. Электронный парамагнитный резонанс и физика плазмы: Избранные труды. М.: Наука, 1990. 343 с.

[13] Курбанов М.А., Султанахмедова И.С., Алиев Г.Г., Гейдаров Г.М. // ЖТФ. 2009. Т. 79. Вып. 7. С. 63.

[14] Керимов М.К., Керимов Э.А., Мусаева С.Н., Панич А.Е., Курбанов М.А. // ФТТ. 2007. Т. 49. Вып. 5. С. 877-880.

[15] Сергеев Г.Б. Нанохимия. М.: МГУ, 2003. 288 с.

[16] Лайнс М., Гласс А. Сегнетоэлектрики и родственные им кристаллы. М.: Мир, 1981. 735 с.

[17] Рез И.С., Поплавко Ю.М. Диэлектрики. Основные свойства и применение в электронике. М.: Радио и связь, 1989. $288 \mathrm{c}$.

[18] Гольдаде В.А., Пинчук Л.С. Электретные пластмассы: Физика и материаловедение. Минск: Наука и техника, 1987. $231 \mathrm{c}$. 